ISSN 0258-7122

Bangladesh J. Agril. Res. 38(1): 71-76, March 2013

\title{
STUDIES ON GENETIC DIVERGENCE IN MAIZE (Zea mays) INBREDS
}

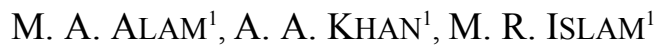 \\ K. U. AHMED ${ }^{1}$ AND A. B. M. KHALDUN ${ }^{2}$
}

\begin{abstract}
Genetic divergence in 17 CIMMYT Maize inbred lines including one check were assessed based on some morphological traits and grain yield using Mahalanobis' $\mathrm{D}^{2}$-statistics. The experiment was carried out in alpha lattice design with two replications at Regional Agricultural Research Station, Ishurdi Pabna during the winter 2010-2011. The genotypes were grouped into four clusters. The cluster II contained the highest number of lines (6), while the cluster I contained only single genotype. The maximum inter-cluster distance was noticed between the cluster I and IV and minimum between cluster I and II. The highest intra-cluster distance was observed in the cluster IV and lowest in cluster I. The genotypes in the cluster III showed better performances having shorter growth duration, short stature, shortest ear height, better shelling percentage and reasonable yielding ability. It is expected that crossing of inbred lines belonging high to medium $\mathrm{D}^{2}$ values may tend to produce high heterosis for yield. Ear aspect had the greatest contribution to the genetic divergence. Days to pollen shedding, silking, maturity, and 1000-grain weight were found to be responsible for primary differentiation.
\end{abstract}

Keywords: Maize, inbred, divergence, clusters, and PCA.

\section{Introduction}

Inbred lines are the prerequisite for hybrid variety development in crop plants. For developing high yielding hybrids in maize, inbred lines need to be evaluated for their diverged gene pool. Assessment on genetic diversity among the genotypes is important for planning an effective hybrid breeding program as the genetically diverged genotypes are known to produce high heterotic effects. It has become possible to quantify magnitude of genetic diversity among germplasm with the help of advanced biometrical methods such as multivariate analysis (Rao, 1952) based on Mahalanobis' (1936) $\mathrm{D}^{2}$ statistics. A number of maize inbred lines from CIMMYT needed assessment of variation among them for evaluation of their potential use in hybrid breeding programs. With this view, diversity among 17 maize inbred lines was studied using multivariate approaches of analysis of variation.

${ }^{1}$ Scientific Officer, Regional Agricultural Research Station, Bangladesh Agricultural Research Institute (BARI), Ishurdi, Pabna, ${ }^{2}$ Scientific Officer, Plant Breeding Division, BARI, Gazipur 1701, Bangladesh. 


\section{Materials and Method}

Seventeen exotic inbred lines of maize (Zea mays) were grown in RCBD design with two replications at Regional Agricultural Research Station, Ishurdi Pabna during the winter 2010-2011. Unit plot size was $3 \mathrm{~m}$ long with 2 rows maintaining $100 \mathrm{~cm}$ spacing. After thinning one healthy plant was kept in each hill. Intercultural operations were done at appropriate time according to the necessity. Data were recorded on yield and different yield contributing traits such as, days to pollen shedding, days to silking, days to maturity, plant height, ear height, plant and ear aspect (average marking based on overview of plant and ear), thousand grain weight and shelling \%. Data were subjected to analysis of Mahalanobis' D2-statistics. Intra-cluster and inter-cluster distance, cluster mean and contribution of each trait to the divergence were estimated as suggested by Singh and Chaudhary (1985).

\section{Results and Discussion}

The variation among the genotypes of seventeen lines was studied on multivariate scale using Mahalanobis, $\mathrm{D}^{2}$-statistics. Assuming the $\mathrm{D}^{2}$-values as $\chi^{2}$, it appears that there were significant variations among all the genotypes. Seventeen genotypes were grouped into four clusters, which are presented in the Table 1. The cluster 2 was the largest, containing six genotypes. Each of the clusters III and IV contained five and cluster I contained only one genotype. Average intra and inter cluster distance of four clusters are presented in Table 2. The magnitude of intra cluster distances indicated the extent of genetic diversity among genotypes within the same cluster. The distance between clusters were more than the intra clusters distances indicating that diversity in between clusters was more than within clusters. The highest distance was obtained between the cluster I and IV (22.99) indicating the wider genetic divergence between these two clusters. It was followed by the distance between the clusters II and IV, I and III, II and III. The cluster I had the highest distance from the rest indicating that the genotype in the cluster I was distinctly different from others. The distance between cluster I and II was minimum (6.45) followed by the distance between the clusters III and IV (9.30) indicating that the genotypes belonging to these clusters were comparatively less diverse. Thus crossing of genotypes from these two clusters may not produce high level of heterotic expression in the $F_{1}$ 's and broad-spectrum of variability in segregating $\left(\mathrm{F}_{2}\right)$ populations. Clusters with comparatively less magnitude of divergence showed instability, while widely divergent clusters remained distinct in different environments (Somayajulu et al., 1970; Raut et al., 1985 and Singh et al., 1980). Parents for hybridization could be selected on the basis of large inter-cluster distance for isolating useful recombinants in the segregating generations. Increasing parental distance implies a greater number of constraining alleles at the desired loci, and then to the extent 
that these loci recombing in the $F_{2}$ and $F_{3}$ generations, following a cross of distantly related parents, the greater will be the opportunities for successful selection for any character of yield interest (Ghaderi et al., 1984).

Table 1. Distribution of $\mathbf{1 7}$ genotypes of maize inbreds in $\mathbf{4}$ clusters.

\begin{tabular}{l|c|l}
\hline \multicolumn{1}{c|}{ Cluster } & No. of genotypes & \multicolumn{1}{c}{ Entry nos. } \\
\hline Cluster I & 1 & 5 \\
Cluster II & 6 & $2,3,6,8,9$ and 11 \\
Cluster III & 5 & $4,7,13,14$ and 16 \\
Cluster IV & 5 & $1,10,12,15$ and 17 \\
\hline
\end{tabular}

Table 2. Average intra and inter cluster distances in maize inbreds.

\begin{tabular}{l|c|c|c|c}
\hline & Cluster I & Cluster II & Cluster III & Cluster IV \\
\hline Cluster I & 0.00 & 6.456 & 13.692 & 22.993 \\
Cluster II & & 0.6371 & 11.573 & 20.186 \\
Cluster III & & & 0.5664 & 9.303 \\
Cluster IV & & & & 0.718
\end{tabular}

Principal Component Analysis (PCA) also helps in assessment of diversity in multivariate scales. In PCA, the first two components were found to contribute $96.93 \%$ of the variation. Therefore, scores obtained for the first two components were plotted against two main axes and then superimposed with clustering (Fig. $1)$. This clustering pattern confirmed the results obtained by $D^{2}$-analysis.

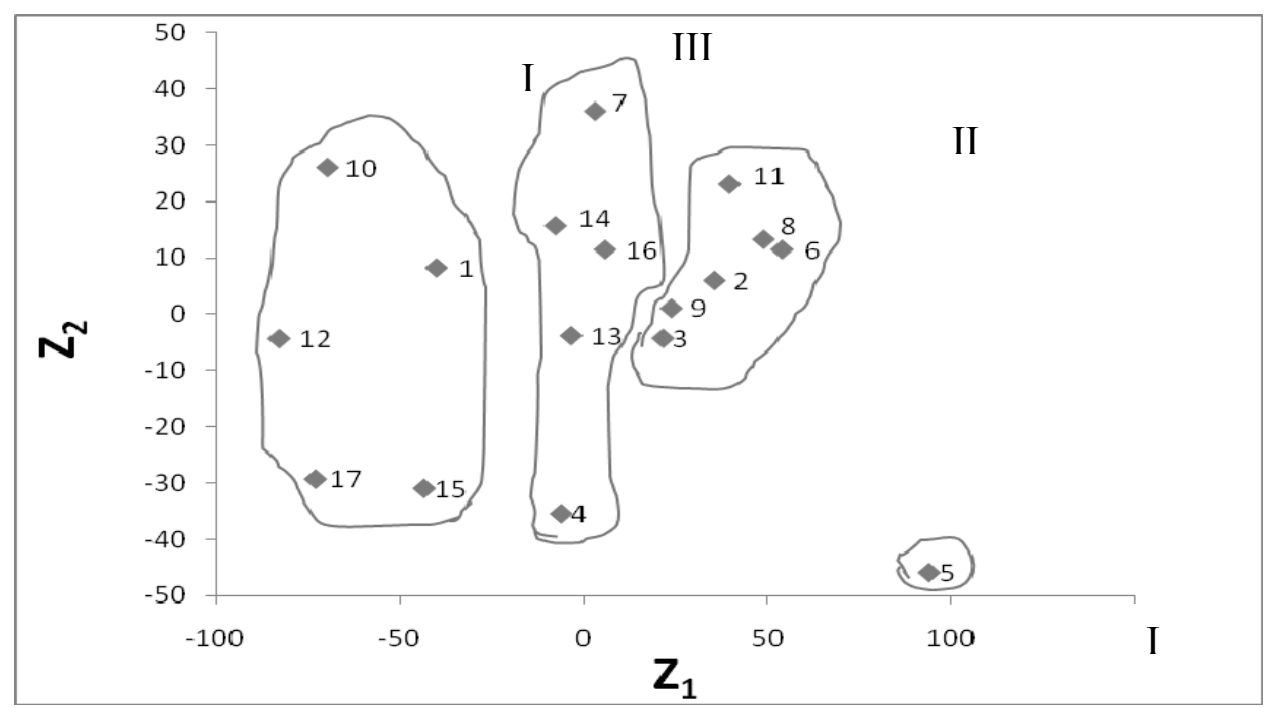

Fig. 1. Scatter distribution of 17 maize inbreds based on their principal components scores superimposed with clustering $(1 \ldots \ldots 17=$ Serial no. of the lines $)$. 
Contributions of characters towards divergence were estimated through canonical variate analysis. In this method, vectors of canonical roots were calculated to represent the genotypes in the graphical form (Rao, 1952). The coefficients pertaining to the different characters in the first two canonical roots are presented in Table 3 . The positive absolute values of the two vectors revealed that ear aspect had the greatest contribution to genetic divergence. The negative values for the two vectors for plant height, ear height, plant aspect, shelling \%, and yield indicated the least responsibility of both the primary and secondary differentiations. However the positive absolute values of vector-1 and negative absolute value for vector- 2 for the characters like days to pollen shedding, days to silking, days to maturity and 1000-grain weight indicated the responsibility of primary differentiation.

Table 3. Contribution of characters towards divergence in maize inbreds.

\begin{tabular}{lccc}
\hline \multicolumn{1}{c}{ Traits } & Vector I & Vector II \\
\hline Days to pollen shedding & 0.4193 & -0.3265 \\
Days to silking & 0.4355 & -0.2797 \\
Days to maturity & 0.4397 & -0.0171 \\
Plant height & -0.1583 & -0.4853 \\
Ear height & -0.0580 & -0.3736 \\
Plant aspect & -0.2927 & -0.1376 \\
Ear aspect & 0.1260 & 0.4052 \\
1000-grain wt & 0.4350 & -0.1795 \\
Shelling \% & -0.2111 & -0.4028 \\
Yield (t/ha) & -0.2784 & -0.2493 \\
\hline
\end{tabular}

Table 4. Cluster means for yield and yield contributing characters in maize inbreds.

\begin{tabular}{lccccc}
\hline \multicolumn{1}{c}{ Traits } & Cluster I & Cluster II & Cluster III & Cluster IV \\
\hline Days to pollen shedding & 108 & 105 & 103.4 & 102.1 \\
Days to silking & 108 & 106.17 & 103.2 & 102.3 \\
Days to maturity & 153 & 152.92 & 150.8 & 149.9 \\
Plant height & 180.35 & 136.22 & 142.77 & 150.38 \\
Ear height & 80.7 & 51.95 & 50.64 & 61.13 \\
Plant aspect & 2 & 2.04 & 2.05 & 2.35 \\
Ear aspect & 2 & 2.21 & 2.5 & 2.4 \\
1000-grain weight & 417.6 & 359.56 & 320.97 & 261.11 \\
Shelling \% & 75.74 & 68.88 & 71.82 & 71.71 \\
Yield (t/ha) & 5.15 & 3.42 & 4.79 & 5.04 \\
\hline
\end{tabular}

Mean values of cluster for yield and its different contributing characters are presented in the table 4. It appears that the early maturing genotypes were included in the cluster IV followed by cluster III. The dwarf genotypes were included in the cluster II followed by cluster III and the tall genotypes include in the cluster I. Lowest ear height were included in cluster III and highest in I. The bold grain size was found in cluster I and smallest in cluster IV. The shelling 
percentage was highest in cluster I and lowest in cluster II. The highest yield was produced by the cluster I and that of lowest yield was produced by the genotypes of the cluster II followed by cluster III. Considering all the characters it appears that the genotypes in the cluster III had good performance. The genotypes in this cluster had shorter growth duration, short statured plant, shortest ear height, intermediate grain size, better shelling percentage and reasonable yielding ability. The performance of individual lines is presented in Table 5.

Table 5. Mean performance of 17 lines of maize for $\mathbf{1 0}$ characters with statistical analysis.

\begin{tabular}{|c|c|c|c|c|c|c|c|c|c|c|}
\hline Lines & DPS & DS & DM & $\begin{array}{c}\mathrm{PH} \\
(\mathrm{cm})\end{array}$ & $\begin{array}{c}\mathrm{EH} \\
(\mathrm{cm})\end{array}$ & PA & EA & \begin{tabular}{|c|}
$\begin{array}{c}\text { TKW } \\
(\mathrm{g})\end{array}$ \\
\end{tabular} & $\begin{array}{c}\text { Shelling } \\
\%\end{array}$ & \begin{tabular}{|c|}
$G Y$ \\
$(\mathrm{t} / \mathrm{ha})$
\end{tabular} \\
\hline 2 & & 4 & 1 & 8.45 & 38.80 & 75 & 3.25 & 282.55 & 73.73 & 4.56 \\
\hline 0 & & & & 4.85 & 58.20 & & 50 & 0 & 76 & 2.89 \\
\hline 5 & $5 \quad 106$ & 106 & 154 & 147.36 & 59.14 & 0 & 00 & 344.15 & .02 & 2.24 \\
\hline LRCW & 105 & & 152 & 175.20 & 74.70 & 00 & 2.25 & 317.40 & 1.93 & 4.46 \\
\hline & 108 & 10 & 153 & 180.35 & 80.70 & 00 & 2.00 & 417.60 & 75.74 & 5.43 \\
\hline LRCW4 & 107 & 108 & 150 & 137.10 & 44.55 & 25 & 2.00 & 376.25 & 72.21 & 6.16 \\
\hline ML498 & 103 & 104 & 51 & 111.75 & 39.70 & 25 & 3.00 & 324.85 & 70.25 & 5.05 \\
\hline LRC & 109 & 11 & & 130.65 & 50.35 & 0 & & 370.70 & 70.82 & 3.99 \\
\hline LRC & 105 & 10 & 150 & 147.05 & 49.90 & 2.75 & 1.50 & 346.50 & 73.64 & 5.34 \\
\hline & & & & 122.40 & & & & 252.45 & .52 & 5.61 \\
\hline LR & 103 & 10 & 1 & 120.30 & 49.55 & 50 & 3.25 & 361.65 & 60.81 & 2.83 \\
\hline LRC & 103 & 10 & 148 & 153.60 & 55.35 & 75 & 25 & 240.05 & 7.45 & 5.88 \\
\hline LR & 10 & 10 & & 153.30 & 51.65 & 50 & 2.75 & 319.45 & 67.10 & 6.30 \\
\hline CLRCW97 & 102 & 103 & 152 & 135.75 & 41.70 & 2.75 & 2.50 & 314.75 & 75.05 & 5.34 \\
\hline $\mathrm{Ml}$ & 104 & & & 159.40 & 89.90 & & & 279.75 & 70.30 & 6.52 \\
\hline MI & 103 & 102 & 150 & 137.85 & 45.45 & .75 & 2.00 & 328.40 & 74.76 & 5.55 \\
\hline 3IL 79 & 100 & 10 & 146 & 168.05 & 76.30 & & 00 & 250.75 & 77.56 & 5.5 \\
\hline Range & $\begin{array}{c}100- \\
109\end{array}$ & $\begin{array}{c}101- \\
110\end{array}$ & $146-$ & $\begin{array}{c}108.8- \\
182.1\end{array}$ & $\begin{array}{l}36.4- \\
90.7\end{array}$ & 125 & $1-5.0$ & $\begin{array}{c}234.3- \\
422.1\end{array}$ & $\begin{array}{c}58.35- \\
77.85\end{array}$ & $\begin{array}{c}2.17- \\
7.02\end{array}$ \\
\hline Mea & 103.88 & 104.30 & 151.52 & 144.86 & 56.40 & .11 & 2.30 & 323.78 & 70.89 & 4.91 \\
\hline SE & 0.38 & 0.51 & 1.04 & 2.74 & 1.76 & 0.36 & 0.23 & 19.57 & 1.05 & 0.46 \\
\hline Level of & * & & $* *$ & ** & $*$ & $*$ & ** & *** & $* *$ & ** \\
\hline $\mathrm{CV}($ & & & 1 & 2.1 & . & & 10.0 & 0.0 & 2.1 & 13.3 \\
\hline LSD & 1.16 & 1.52 & 3.13 & 8.23 & 5.30 & 1.09 & 0.67 & 58.69 & 3.16 & 1.39 \\
\hline
\end{tabular}

N.B.: DPS=Days to pollen shed, DS=Days to silk, DM=Days to maturity, $\mathrm{PH}=\mathrm{Plant}$ height $(\mathrm{cm}), \mathrm{EH}=$ Ear height $(\mathrm{cm}), \mathrm{PA}=$ Plant aspect $(1-5$ scale, where 1 is best and 5 worst), EA $=$ Ear aspect (Scale same as PA), TKW= 1000-kernel weight, $\mathrm{GY}=$ Grain yield $(\mathrm{t} / \mathrm{ha})$ 
Genetically distant parents usually able to produce higher heterosis (Falconar, 1960; Moll et al., 1962 and Mian and Bhal 1989). Endang et al., (1971) stated that the clustering pattern could be utilized in choosing parents for cross combinations which likely to generate the highest possible variability for effective selection of various economic traits. Keeping this in view, the findings from the present study indicated that the cluster I and IV, II and IV, I, and III showed higher distance between them. Parental material selection from these clusters would give high manifestation of heterosis as well as wide spectrum of variation when they are hybridized.

\section{References}

Endang, S., S. Andani, and H. Nasoetion. 1971. Multivariate classification of some rice (Oryza sativa L.) varieties and strain on yield components. Int. Rice comm. Newst. 20: $26-34$.

Falconer, D. S. 1960. Introduction to Quantitative Genetics. Oliver and Bond, London. P. 304.

Ghaderi, A., M. W. Adams and A. M. Nassib. 1984. Relationship between genetic distance and heterosis for yield and morphological traits in dry edible bean and faba bean. Crop Sci. 24: 37-24.

Mahalanobis, P. C. 1936. On the generalized distance in statistics. Nat. Inst. Sci. Ind. B. $Z .: 49-55$.

Mian, M. A. K. and P. N. Bhal. 1989. Genetic divergence and hybrid performance in cheakpea. Indian J. Genet. 49(1): 119-129.

Moll, R. H., W. S. Salhwana and H. R. Robinson. 1962. Heterosis and genetic diversity in variety crosses in crop maize. Crop Sci. 2: 197-198.

Rao, C. R. 1952. Advanced Statistical Method in Biometric Research. Ednl. John Wiley and Sons, New York. Pp. 36-38.

Raut, V. M, V. S. P. Rao, V. P. Patel and G. B. Deodikar. 1985. Genetic divergence in Triticum durum. Indian J. Genet. 45: 141-151.

Singh, D., P. Kumar and B. P. S. Chandan. 1980. Genetic diversity for some quantitative characters in barley. Indian J. Genet. 40(2): 391-395.

Singh, R. K. and B. D. Chaudhary. 1985. Biometrical methods in quantitative genetic analysis. Kalyani Publ., New Delhi. pp. 102-157.

Somayajulu, P. L. N., A. B. Joshi and B. R. Murty. 1970. Genetic divergence in wheat. Indian J. Genet. 30(1): 47-58. 